\title{
Current Guidelines, Common Clinical Pitfalls, and Future Directions for Laboratory Diagnosis of Lyme Disease, United States
}

\author{
Andrew Moore, ${ }^{1}$ Christina Nelson, ${ }^{1}$ Claudia Molins, Paul Mead, Martin Schriefer
}

\begin{abstract}
$\underset{\text { Mndinatind }}{\text { Medscape ACTIVITY }}$
Medscape, LLC is pleased to provide online continuing medical education (CME) for this journal article, allowing clinicians the opportunity to earn CME credit.

This activity has been planned and implemented in accordance with the Essential Areas and policies of the Accreditation Council for Continuing Medical Education through the joint providership of Medscape, LLC and Emerging Infectious Diseases. Medscape, LLC is accredited by the ACCME to provide continuing medical education for physicians.

Medscape, LLC designates this Journal-based CME activity for a maximum of 1.0 AMA PRA Category 1 Credit(s) ${ }^{T M}$. Physicians should claim only the credit commensurate with the extent of their participation in the activity.

All other clinicians completing this activity will be issued a certificate of participation. To participate in this journal CME activity: (1) review the learning objectives and author disclosures; (2) study the education content; (3) take the post-test with a $75 \%$ minimum passing score and complete the evaluation at http://www.medscape.org/journal/eid; (4) view/print certificate.

Release date: June 15, 2016; Expiration date: June 15, 2017

Learning Objectives

Upon completion of this activity, participants will be able to:

- Distinguish current US testing guidelines for Lyme disease, based on a review

- Determine appropriate use and interpretation of tests for Lyme disease

- Identify recent developments in Lyme disease diagnostics

CME Editor

Thomas J. Gryczan, MS, Technical Writer/Editor, Emerging Infectious Diseases. Disclosure: Thomas J. Gryczan, MS, has disclosed no relevant financial relationships.

CME Author

Laurie Barclay, MD, freelance writer and reviewer, Medscape, LLC. Disclosure: Laurie Barclay, MD, has disclosed the following relevant financial relationships: owns stock, stock options, or bonds from Pfizer.

Authors

Disclosures: Andrew Moore; Christina Nelson, MD, MPH; Claudia Molins, PhD; Paul Mead, MD, MPH; and Martin Schriefer, PhD, have disclosed no relevant financial relationships.
\end{abstract}

Author affiliations: University of Virginia School of Medicine, Charlottesville, Virginia, USA (A. Moore); Centers for Disease Control and Prevention, Fort Collins, Colorado, USA (C. Nelson,

C. Molins, P. Mead, M. Schriefer)
In the United States, Lyme disease is caused by Borrelia burgdorferi and transmitted to humans by blacklegged ticks. Patients with an erythema migrans lesion and epidemiologic risk can be given a diagnosis without laboratory testing. 
For all other patients, laboratory testing is necessary to confirm the diagnosis, but proper interpretation depends on symptoms and timing of illness. The recommended laboratory test in the United States is 2-tiered serologic analysis consisting of an enzyme-linked immunoassay or immunofluorescence assay, followed by reflexive immunoblotting. Sensitivity of 2 -tiered testing is low (30\%-40\%) during early infection while the antibody response is developing (window period). For disseminated Lyme disease, sensitivity is $70 \%-100 \%$. Specificity is high (>95\%) during all stages of disease. Use of other diagnostic tests for Lyme disease is limited. We review the rationale behind current US testing guidelines, appropriate use and interpretation of tests, and recent developments in Lyme disease diagnostics.

L yme disease is a tickborne disease caused by spirochetes within the Borrelia burgdorferi sensu lato species complex (1). In the United States, Lyme disease is caused by B. burgdorferi sensu stricto and B. mayonii and is transmitted to humans by infected Ixodes scapularis or I. pacificus ticks (commonly known as blacklegged ticks) (2). Lyme disease is the most common vectorborne disease in the United States and causes an estimated 300,000 illnesses annually $(3,4)$. Cases occur primarily in the northeast and upper midwest regions (Figure 1); however, ecologic and environmental changes have catalyzed a gradual geographic expansion (5).

There are 3 stages of $B$. burgdorferi infection: early localized, early disseminated, and late disseminated. The classic sign of localized infection is erythema migrans (EM), which is defined as a gradually expanding annular lesion $\geq 5 \mathrm{~cm}$ in diameter. Approximately $70 \%-80 \%$ of persons with Lyme disease have EM $(1,6)$. Accompanying signs and symptoms might include fever, lymphadenopathy, myalgias, or arthralgias. If the infection is not treated, the bacteria might spread hematogenously and cause early disseminated Lyme disease, which can manifest as multiple EM skin lesions, facial palsy, meningitis, or carditis. Recurrent large-joint arthritis is the hallmark of late disseminated disease. Late neurologic Lyme disease is uncommon in the United States. Symptoms might include peripheral neuropathy, encephalopathy, or encephalomyelitis.

Patients who have a lesion consistent with EM and live in or have traveled to Lyme-endemic areas can be given a diagnosis without laboratory testing (6). In the absence of EM, all other manifestations of Lyme disease

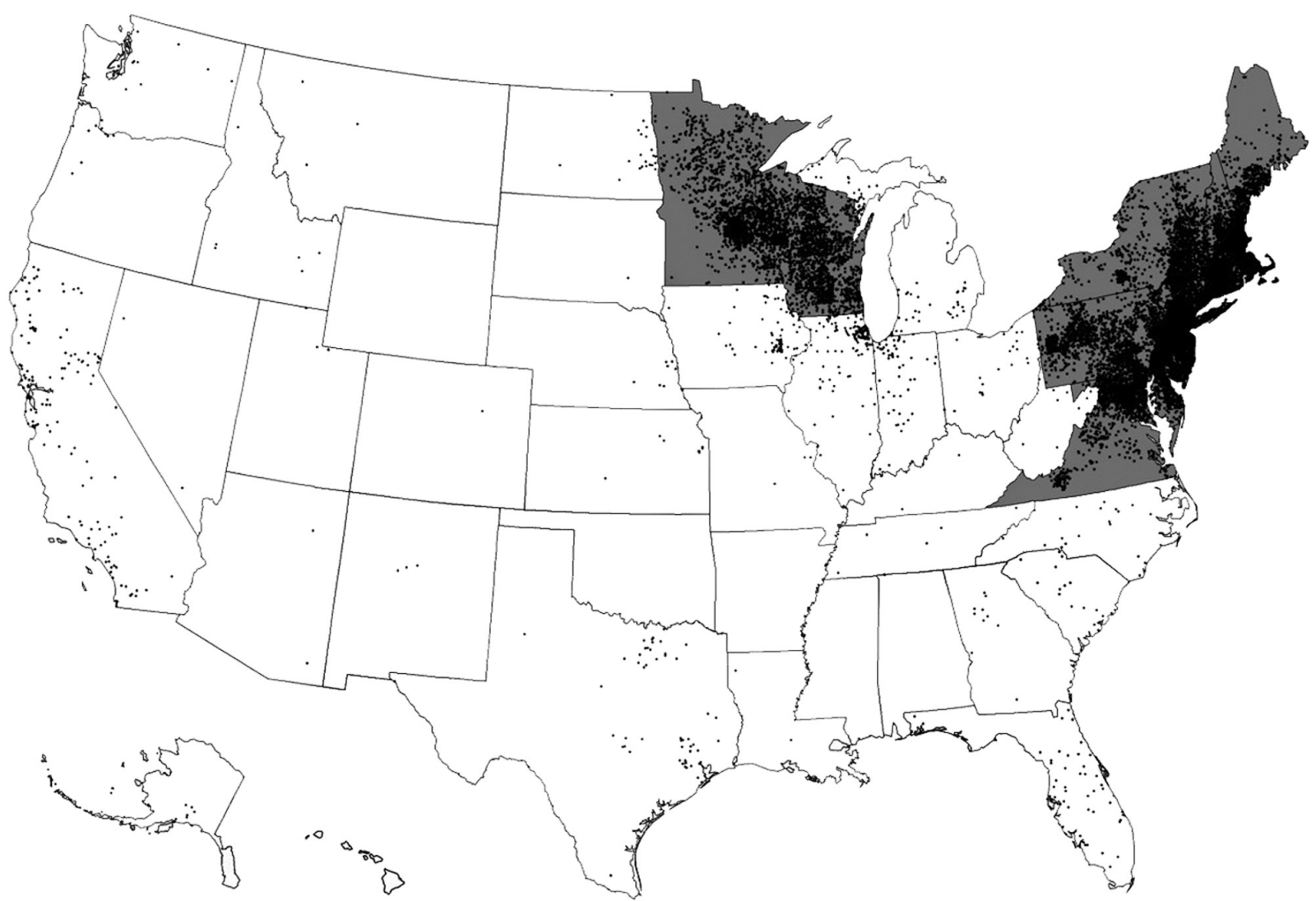

Figure 1. Lyme disease cases (black dots) reported by surveillance, United States, 2005-2010. One dot is placed randomly within the county of residence for each confirmed case. States with the highest incidence of clinician-diagnosed Lyme disease in a large health insurance claims database (gray areas) are also shown. Transmission also occurs in small regions of northern California, Oregon, and Washington. Adapted from (4). 
require serologic analysis to confirm the diagnosis. The recommended approach for laboratory diagnosis of Lyme disease is a 2-tiered serologic test comprised of an enzyme-linked immunoassay (EIA or ELISA) or immunofluorescence assay (IFA), followed by a reflex Western immunoblot (7). When used in accordance with current testing guidelines (7), 2-tiered serologic testing is a valuable and highly specific clinical tool for diagnosis of disseminated Lyme disease. Confusion exists, however, among patients and clinicians concerning appropriate use and interpretation of this and other diagnostic tests for Lyme disease $(8,9)$. In this article, we review the rationale behind current United States testing guidelines, use and interpretation of 2-tiered serologic analysis and other tests in the clinical setting, and recent developments in the field of Lyme disease diagnostics.

\section{Historical Perspective}

The discovery of $B$. burgdorferi as the causative agent of Lyme disease in 1982 prompted development of numerous tests by clinical and private laboratories. Because spirochetes only transiently enter the bloodstream of infected persons in small numbers, direct detection of B. burgdorferi by PCR or culture has been challenging (10). For this reason, most diagnostic test development has focused on indirect detection of infection by assessing the antibody response of the patient.

Initially, the variety of serologic tests and lack of concordance among different methods necessitated standardization. In 1994, leading experts convened at the Second National Conference on the Serologic Diagnosis of Lyme Disease (Dearborn, Michigan, USA) to review the current evidence and devise a standard testing strategy (7). After evaluating the evidence, it became clear that no single test was sufficient on its own. To maximize clinical utility and specificity, the conference diagnostic working group ultimately decided on a 2-tiered serologic testing algorithm (Figure 2). The first tier uses a highly sensitive EIA or IFA that, if the result is positive or equivocal, is

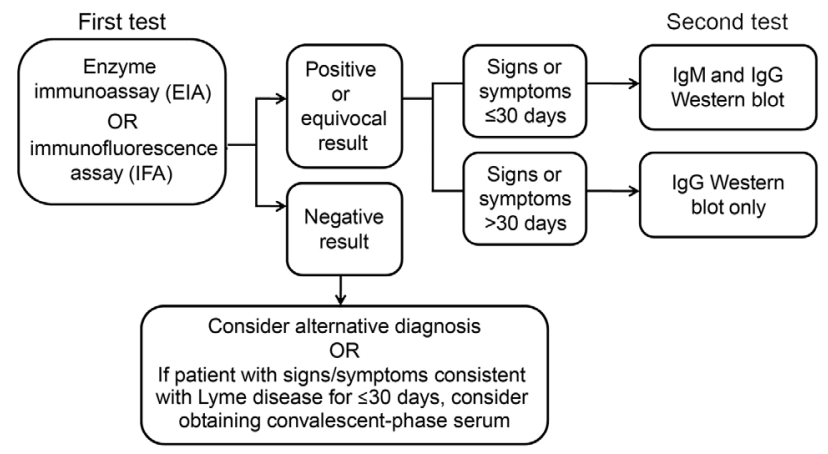

Figure 2. Two-tiered testing for Lyme disease, United States. Adapted from (7). followed by a highly specific Western immunoblot as the second-tier test (7). Western immunoblot was included in response to a multicenter evaluation of laboratories performing Lyme disease testing, which found that using Western immunoblot in addition to EIA increased specificity to $>98 \%$, reducing false-positive results produced by the first-tier EIA (11).

\section{Two-Tiered Serologic Testing}

When performed and interpreted in accordance with current guidelines, 2-tiered serologic analysis has a sensitivity of $\approx 70 \%-100 \%$ and a specificity $>95 \%$ for disseminated Lyme disease (Table) $(6,12-15)$. Thus, this analysis is the standard of care in diagnosing disseminated Lyme disease but requires appropriate clinical judgment when ordering the test and interpreting the results. To this end, understanding the underlying testing procedure is beneficial.

\section{First Tier}

The first-tier test involves measuring the overall antibody response (typically IgM and $\operatorname{IgG}$ ) of a patient to B. burgdorferi antigens (7). Although both the EIA and IFA have been cleared by the Food and Drug Administration (FDA; Silver Spring, MD, USA) as first-tier tests, laboratories most commonly perform EIA because it is more easily automated. An additional benefit of EIA is that it provides a quantitative value of the relative concentration of antibodies in the serum of a patient compared with that of a control, which enables use of objective cutoff values (10).

In the United States, most laboratories use a wholecell sonicate preparation of $B$. burgdorferi as antigen for the EIA. This test approach has high sensitivity because of multiple antigens in whole-cell sonicate preparation. However, because some of these antigens are cross-reactive with antigens from the host or other pathogens, specificity of the EIA alone is not optimal (10).

Additional FDA-cleared EIAs that use as few as 1 to several antigens, which results in a higher specificity and similar sensitivity than that for whole-cell sonicate EIAs, have recently become commercially available. The cell surface variable-major protein-like sequence expressed (VlsE) lipoprotein and its sixth invariable region, the C6 peptide, are 2 FDA-cleared EIA antigens that are gaining popularity $(16,17)$. These Borrelia antigens are highly conserved and immunogenic among all Lyme borreliosis species and strains, and cause an early antibody response useful for diagnostic testing (18).

\section{Second Tier}

Similar to EIA, the second-tier immunoblot is a serologic test that detects antibodies produced against $B$. burgdorferi (10). Unlike EIA, however, the immunoblot detects 
Therefore, presence of $1 \mathrm{IgM}$ band or $\leq 4 \mathrm{IgG}$ bands does not indicate an overall positive result. Overinterpreting a small number of antibody bands leads to reduced specificity and potential misdiagnosis $(9,20)$.

\section{Additional Diagnostic Tests}

\section{Antibody Testing of Cerebrospinal Fluid}

Testing for intrathecal antibody production is integral in the diagnosis of Lyme neuroborreliosis in Europe, where multiple Borrelia species and high background seroprevalence limit the usefulness of serologic analysis (1). In the United States, the presence of serum antibodies in the appropriate clinical setting is highly sensitive and specific for Lyme neuroborreliosis, making 2-tiered serologic analysis the diagnostic test of choice in most instances $(6,10)$. Adjunctive testing for intrathecal antibody production is highly specific and might be helpful in confirming the diagnosis, particularly in regions of high seroprevalence. However, a negative result is insufficient to rule out Lyme neuroborreliosis except in cases of encephalomyelitis.

When testing for intrathecal antibodies, it is essential to note that antibodies in serum are passively transferred to cerebrospinal fluid (CSF) in some patients with Lyme disease $(10,21)$. To control for this transfer, CSF and serum should be collected on the same day and diluted to match the total protein or IgG concentration. A CSF/serum $\operatorname{IgG}$ EIA optical density ratio $>1.0$ indicates active intrathecal antibody production.

\section{PCR and Culture}

PCR can provide highly specific evidence of $B$. burgdorferi nucleic acid in a variety of samples, including synovial fluid, skin biopsy tissue, blood, and CSF $(10,22)$. However, its clinical utility is limited by low sensitivity (particularly for blood and CSF samples) and its potential for contamination $(10,23)$.

Synovial fluid PCR is $>75 \%$ sensitive for Lyme arthritis and might be useful in conjunction with other synovial fluid analyses to differentiate Lyme arthritis from other arthritides $(10,22)$. Comparatively, PCR of CSF is substantially less sensitive, which limits its clinical utility. In 1 US study, PCR testing of CSF yielded positive results for only $38 \%$ of patients with early neuroborreliosis and was even less sensitive for late neuroborreliosis (24).

Studies of PCR on blood have found that its high specificity is outweighed by its lack of clinical sensitivity and potential for contamination $(10,22)$. Thus, PCR has not been universally standardized or optimized for diagnosis of Lyme disease. Nevertheless, some clinical laboratories offer PCR testing for Borrelia spp., and PCR of blood has shown utility in detection of the novel genospecies B. miyamotoi and B. mayonii (25).
Because B. burgdorferi is a slow-growing organism, current culturing methods are labor-intensive and have poor sensitivity. Culturing is generally not recommended for purposes other than research or for corroboration of disease acquired in regions previously unrecognized for risk of infection (10).

\section{Clinical Considerations and Common Pitfalls}

\section{Timing of Testing-Window Period}

As with all serologic tests, clinicians must consider the timing of a patient's illness when ordering and interpreting Lyme disease tests (6). Serologic analysis has low sensitivity during the first few weeks of infection while the antibody response is still developing (10). This period is known as the window period and is common to all serologic testing. Patients with illnesses suspicious for early Lyme disease but lacking typical EM can present a diagnostic dilemma because serologic test results might be negative at this point ( 6 ). In these cases, treatment can be administered at the discretion of the clinician, but serologic analysis is necessary to confirm the diagnosis (Figures 2,3).

\section{Background Seropositivity}

Background seropositivity is a major consideration when testing for Lyme disease. In a seroepidemiologic study conducted in New York, $5 \%$ of study participants were found to have antibodies against B. burgdorferi (26). Seropositivity can result from previous exposure because IgM and IgG against $B$. burgdorferi can remain for many years after initial infection (which, incidentally, is why serologic testing is not useful as a test of cure) $(26,27)$. However, in the seroepidemiologic study in New York, $59 \%$ of seropositive patients denied a prior diagnosis of Lyme disease (26). In such persons, seropositivity might indicate a false-positive result or be due to a prior undiagnosed infection that either resolved spontaneously or was treated incidentally with antimicrobial drugs prescribed for another indication.

\section{Reinfection}

Because of antibody persistence, serologic diagnosis of patients with possible reinfection poses a major dilemma for clinicians (28). In cases of suspected reinfection, a detailed history and physical examination, including a thorough skin examination, are essential because most patients will have EM. For patients without EM, serologic analysis is still recommended but results should be interpreted with caution. In these cases, it might be helpful to conduct acute-phase and convalescent-phase serologic analysis to detect an increase in EIA titer or an increase in the number of antibody bands that might indicate active infection $(10,28)$. 
High pretest probability. Results not likely to change management.

- Intermediate pretest probability. True positive is more likely than false positive.

- Low pretest probability. False positive is more likely than true positive.
Possible Lyme disease

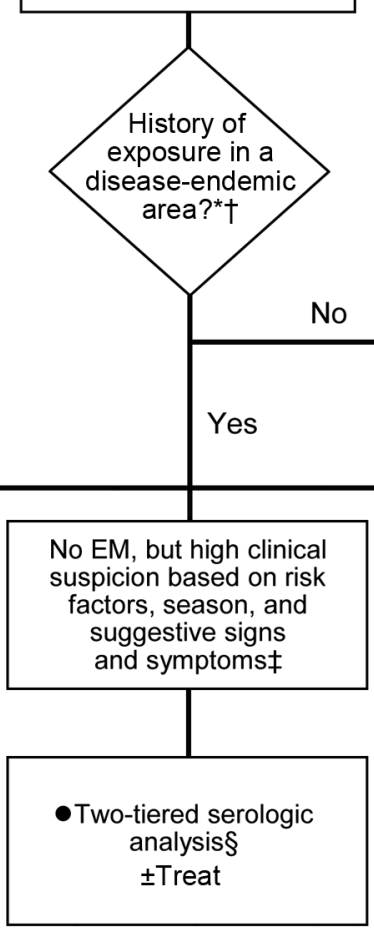

Consider alternative diagnosis for symptoms (e.g., STARI for EM-like rash in the southern United States)

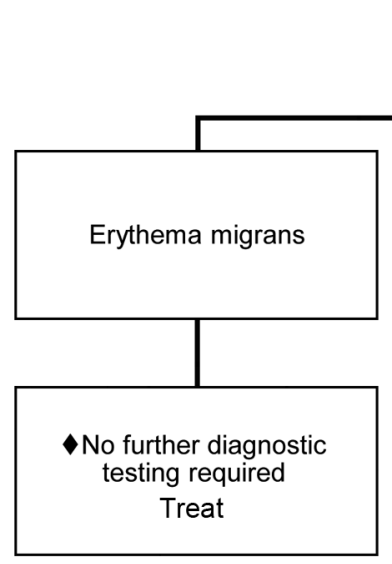

\section{Exposure and Pretest Probability}

When determining whether to test for Lyme disease, clinicians must consider a patient's pretest probability (Figure 3) (8). Even highly specific tests can show false-positive results when performed for patients with low pretest probability.

The most crucial factor governing pretest probability for Lyme disease is exposure history. A recent retrospective cohort study by Lantos et al. reported a positive predictive value for Lyme disease serologic analysis in the Duke University hospital system in North Carolina (a lowincidence state) of only $10 \%$ for patients with no history of recent travel to a disease-endemic region (29). In addition, only $0.7 \%$ of patients without recent travel history who had potential signs of disseminated infection (arthritis, cranial neuropathies, or meningitis) were ultimately given a diagnosis of Lyme disease, which indicated that even clinical signs considered consistent with Lyme disease have poor predictive value in low-incidence regions. Furthermore, even EM-like lesions - once considered pathognomonic for Lyme disease - can be caused by other conditions, such as Southern tick-associated rash illness, a tick-borne illness found primarily in the southeastern United States for which an infectious etiology has not been identified (30).

For these reasons, positive results for Lyme serologic analysis provide little diagnostic value for patients in areas to which this disease is not endemic and with no history of recent travel to disease-endemic areas (Figure 1) $(8,31)$.
Figure 3. Clinical approach to diagnosis of early Lyme disease, United States. STARI; Southern tick-associated rash illness; EM, erythema migrans. *See Figure 1. †Given the gradual geographic expansion of Lyme disease, testing may be warranted for patients with signs and symptoms of Lyme disease who were exposed in areas that border known disease-endemic regions. $\ddagger$ For a more detailed discussion of symptoms as they relate to pretest probability, see section on exposure and pretest probability. §For recommended 2-tiered testing protocol, see Figure 2.

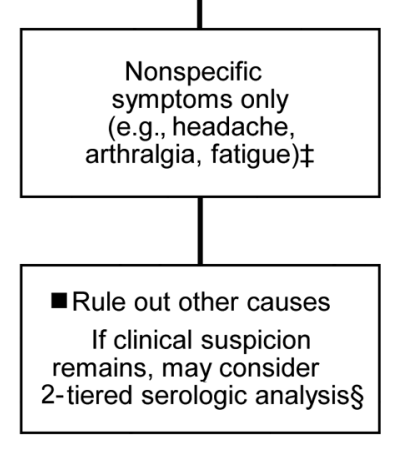

When assessing whether an area is endemic for Lyme disease, it is essential to note that surveillance guidelines classify cases on the basis of the patient's permanent residence, rather than location of exposure (National Notifiable Disease Surveillance System, http://wwwn.cdc.gov/ nndss/conditions/lyme-disease/). A recent study of Lyme disease in low-incidence states found that $84 \%$ of infected patients reported recent travel to high-incidence regions (31). Thus, although cases have been reported in all 50 states, this finding does not indicate that Lyme disease is endemic to all states.

In addition to exposure history, patient signs and symptoms provide useful information regarding pretest probability (6). Patients with EM who live in or have traveled to Lyme disease-endemic areas can be given a diagnosis without serologic testing. For patients without EM, headache and arthralgias are the most common symptoms of early Lyme disease (32). However, such symptoms are nonspecific and do not justify serologic testing unless clinical suspicion is high. Signs such as cranial nerve palsy, meningitis, carditis, and migratory large joint arthritis are more suggestive of Lyme disease and improve pretest probability for patients with epidemiologic risk for Lyme disease (29). Such signs in at-risk patients generally justify serologic testing. Conversely, gastrointestinal or upper respiratory symptoms are rarely seen in Lyme disease and suggest an alternative diagnosis (32). 


\section{Surveillance versus Clinical Diagnostic Testing}

One misconception is that 2-tiered serologic analysis is intended only for surveillance, rather than patient diagnosis. This misconception is inaccurate and is an apparent conflation of clinical serologic testing recommendations for Lyme disease and the surveillance case definition of the Council of State and Territorial Epidemiologists (7) (http://wwwn.cdc.gov/nndss/conditions/lyme-disease/). Recommendations for 2-tiered testing are meant to aid the diagnosis of individual patients in the clinical setting. Serologic test results might be used by public health officials to determine whether a given illness meets the surveillance case definition, but the methods themselves were not developed for this purpose. Furthermore, for practical reasons, serologic results might be used slightly differently in surveillance than is recommended in the clinical setting. For example, although it is not recommended to perform Western immunoblot without a first-tier EIA for laboratory diagnosis, a positive IgG result by Western immunoblot alone is accepted as laboratory evidence of infection for surveillance purposes (http://wwwn.cdc.gov/nndss/conditions/lyme-disease/). This operational definition enables simplification of reporting practices because it can be difficult to track down records of the first-tier test. However, it does not represent best clinical practice.

\section{Unvalidated Tests and Interpretation Criteria}

Several alternative testing centers use laboratory-developed tests, also known as home brew tests, that are not currently subject to FDA regulations and might not be clinically validated $(9,33)$. Alternative laboratories might also use standard Western immunoblot techniques but apply nonstandard interpretation criteria or fail to perform the recommended first-tier EIA. Unfortunately, many of these alternative laboratories have appealed to patients because they often claim to specialize in testing for tickborne diseases and assert that their tests have better sensitivity than standardized 2-tiered serologic analysis.

False-positive results for alternative tests or unvalidated interpretation criteria can lead to patient confusion and misdiagnosis $(9,20,33)$. A recent evaluation of laboratories by Fallon et al. reported an alarming false-positive rate of $58 \%$ for samples from healthy control patients submitted to an alternative testing center that used unvalidated criteria to interpret IgM and IgG immunoblots (34). Moreover, evaluation of published results from a laboratory claiming to have a new Borrelia culture method demonstrated that results were highly suspicious for laboratory contamination $(33,35)$. Additional alternative tests, such as urine antigen tests and CD57 tests, have also been shown to be inaccurate $(36,37)$.

It is recommended that clinicians only use Lyme disease tests that have been clinically validated and cleared by the FDA $(16,33)$. If there is ever any question regarding testing protocols or interpretation, clinicians should consult an infectious disease specialist.

\section{Future Directions in Diagnostic Testing}

\section{Novel 2-Tiered Algorithms}

A great deal of research has focused recently on improving early diagnosis of Lyme disease and reducing subjectivity inherent in Western immunoblot techniques. When used as a stand-alone test, the C6 EIA is more sensitive than the current 2-tiered test for patients with early Lyme disease ( $64 \%$ vs. $48 \%$ ) but is hampered by decreased specificity ( $98.4 \%$ vs $99.5 \%$ ) and thus is more prone to false-positive results $(12,17)$. To address this issue, Branda et al. proposed a 2-tiered EIA approach consisting of 2 FDA-cleared EIAs: whole-cell sonicate EIA followed by reflex C6 EIA. This approach provided a higher sensitivity for early Lyme disease $(61 \%$ vs. $48 \%$ for 2 -tiered testing) and equivalent specificity (99.5\%) to the current approach (Table) (12). A 2-tiered EIA with VlsE EIA followed by reflex C6 EIA has also been proposed. The ease of automation and straightforward results of 2-EIA approaches make them particularly appealing because they would be easier to perform and eliminate the subjectivity of Western immunoblot. Further research is still needed, but in the future, the 2-tiered EIA approach might prove to be a valid alternative for diagnosis of Lyme disease.

\section{Additional Novel Diagnostic Approaches}

Another approach to improve sensitivity for detection of early Lyme disease involves identifying diagnostic proteins and metabolites in serum of patients with Lyme disease. These methods, referred to as proteomics and metabolomics, respectively, are particularly appealing because they also have the potential to identify biomarkers indicative of cure $(38,39)$. Researchers have also reported promising results using immuno-PCR, which combines the sensitivity of PCR with EIA-based antibody detection (40).

\section{Lyme Serum Repository for Validation of Novel Diagnostic Tests}

When developing new tests or assessing their performance, researchers must have access to well-characterized positive and negative controls. Moreover, it is essential to include samples from patients with diseases that have overlapping clinical features and that are known to be serologically cross-reactive because sensitivity and specificity are heavily dependent on the types of patient samples used. However, collecting and characterizing a wide variety of clinical samples for this purpose can be challenging, costly, and time-consuming. 
To improve availability of serum sample sets to evaluate novel diagnostic tests, the Centers for Disease Control and Prevention (Fort Collins, CO, USA) and the National Institutes of Health (Bethesda, MD, USA) have developed a repository of well-characterized serum samples from patients with Lyme disease (14). The repository includes samples from patients with various stages of Lyme disease; patients with cross-reactive conditions, such as multiple sclerosis and infectious mononucleosis; and healthy controls from both disease-endemic and non-disease-endemic areas. Panels of serum, along with accompanying clinical and laboratory testing results, are now available to researchers for validation of novel diagnostic tests.

\section{Conclusions}

In the United States, 2-tiered serologic analysis is currently the diagnostic test of choice for all patients with signs of extracutaneous Lyme disease. When considering testing, clinicians must take into account the patient's history, timeline of symptoms, and pretest probability to accurately order the test and interpret the test result. Moreover, clinicians should understand the hazards of alternative laboratory tests and only use FDA-cleared diagnostic tests. Ongoing and published research promises to improve diagnosis of early Lyme disease and reduce subjectivity of the second-tier Western immunoblotting.

Mr. Moore is a medical student at the University of Virginia School of Medicine, Charlottesville, Virginia. His primary research interest is improving physician and public understanding of Lyme disease.

\section{References}

1. Stanek G, Wormser GP, Gray J, Strle F. Lyme borreliosis. Lancet. 2012;379:461-73. http://dx.doi.org/10.1016/ S0140-6736(11)60103-7

2. Pritt BS, Mead PS, Johnson DK, Neitzel DF, Respicio-Kingry LB, Davis JP, et al. Identification of a novel pathogenic Borrelia species causing Lyme borreliosis with unusually high spirochataemia: a descriptive study. Lancet Infect Dis. 2016;Feb 5:pii: S1473-3099(15)00464-8.

3. Adams DA, Jajosky RA, Ajani U, Kriseman J, Sharp P, Onwen DH, et al. Summary of notifiable diseases - United States, 2012. MMWR Morb Mortal Wkly Rep. 2014;61:1-121.

4. Nelson CA, Saha S, Kugeler KJ, Delorey MJ, Shankar MB, Hinckley AF, et al. Incidence of clinician-diagnosed Lyme disease, United States, 2005-2010. Emerg Infect Dis. 2015;21:1625-31. http://dx.doi.org/10.3201/eid2109.150417

5. Kugeler KJ, Farley GM, Forrester JD, Mead PS. Geographic distribution and expansion of human Lyme disease, United States. Emerg Infect Dis. 2015;21:1455-7. http://dx.doi.org/10.3201/ eid2108.141878

6. Wormser GP, Dattwyler RJ, Shapiro ED, Halperin JJ, Steere AC, Klempner MS, et al. The clinical assessment, treatment, and prevention of Lyme disease, human granulocytic anaplasmosis, and babesiosis: clinical practice guidelines by the Infectious Diseases Society of America. Clin Infect Dis. 2006;43:1089-134. http://dx.doi.org/10.1086/508667
7. Centers for Disease Control and Prevention. Recommendations for test performance and interpretation from the Second National Conference on serologic diagnosis of Lyme disease. MMWR Morb Mortal Wkly Rep. 1995;44:590-1.

8. Seltzer EG, Shapiro ED. Misdiagnosis of Lyme disease: when not to order serologic tests. Pediatr Infect Dis J. 1996;15:762-3. http://dx.doi.org/10.1097/00006454-199609000-00003

9. Centers for Disease Control and Prevention. Notice to readers: caution regarding testing for Lyme disease. MMWR Morb Mortal Wkly Rep. 2005;54:125 [cited 2016 Mar 14]. http://www.cdc.gov/ $\mathrm{mmwr} /$ preview/mmwrhtml/mm5405a6.htm

10. Aguero-Rosenfeld ME, Wang G, Schwartz I, Wormser GP. Diagnosis of Lyme borreliosis. Clin Microbiol Rev. 2005;18:484 509. http://dx.doi.org/10.1128/CMR.18.3.484-509.2005

11. Craven RB, Quan TJ, Bailey RE, Dattwyler R, Ryan RW, Sigal LH, et al. Improved serodiagnostic testing for Lyme disease: results of a multicenter serologic evaluation. Emerg Infect Dis. 1996;2:136-40. http://dx.doi.org/10.3201/eid0202.960211

12. Branda JA, Linskey K, Kim YA, Steere AC, Ferraro MJ. Twotiered antibody testing for Lyme disease with use of 2 enzyme immunoassays, a whole-cell sonicate enzyme immunoassay followed by a VlsE C6 peptide enzyme immunoassay. Clin Infect Dis. 2011;53:541-7. http://dx.doi.org/10.1093/cid/cir464

13. Wormser GP, Schriefer M, Aguero-Rosenfeld ME, Levin A, Steere AC, Nadelman RB, et al. Single-tier testing with the C6 peptide ELISA kit compared with two-tier testing for Lyme disease. Diagn Microbiol Infect Dis. 2013;75:9-15. http://dx.doi.org/10.1016/j.diagmicrobio.2012.09.003

14. Molins CR, Sexton C, Young JW, Ashton LV, Pappert R, Beard CB, et al. Collection and characterization of samples for establishment of a serum repository for Lyme disease diagnostic test development and evaluation. J Clin Microbiol. 2014;52:3755-62. http://dx.doi.org/10.1128/JCM.01409-14

15. Wormser GP, Levin A, Soman S, Adenikinju O, Longo MV, Branda JA. Comparative cost-effectiveness of two-tiered testing strategies for serodiagnosis of Lyme disease with noncutaneous manifestations. J Clin Microbiol. 2013;51:4045-9. http://dx.doi.org/ 10.1128/JCM.01853-13

16. Food and Drug Administration. Database: search on product code LSR [cited 2015 Jul 17]. http://www.accessdata.fda.gov/scripts/ cdrh/devicesatfda/index.cfm

17. Bacon RM, Biggerstaff BJ, Schriefer ME, Gilmore RD Jr, Philipp MT, Steere AC, et al. Serodiagnosis of Lyme disease by kinetic enzyme-linked immunosorbent assay using recombinant VlsE1 or peptide antigens of Borrelia burgdorferi compared with 2-tiered testing using whole-cell lysates. J Infect Dis. 2003;187:1187-99. http://dx.doi.org/10.1086/374395

18. Liang FT, Steere AC, Marques AR, Johnson BJ, Miller JN, Philipp MT. Sensitive and specific serodiagnosis of Lyme disease by enzyme-linked immunosorbent assay with a peptide based on an immunodominant conserved region of Borrelia burgdorferi VlsE. J Clin Microbiol. 1999;37:3990-6.

19. Aguero-Rosenfeld ME, Nowakowski J, Bittker S, Cooper D, Nadelman RB, Wormser GP. Evolution of the serologic response to Borrelia burgdorferi in treated patients with culture-confirmed erythema migrans. J Clin Microbiol. 1996;34:1-9.

20. Nelson C, Elmendorf S, Mead P. Neoplasms misdiagnosed as “chronic Lyme disease.” JAMA Intern Med. 2015;175:132-3. http://dx.doi.org/10.1001/jamainternmed.2014.5426

21. Steere AC, Berardi VP, Weeks KE, Logigian EL, Ackermann R. Evaluation of the intrathecal antibody response to Borrelia burgdorferi as a diagnostic test for Lyme neuroborreliosis. J Infect Dis. 1990;161:1203-9. http://dx.doi.org/10.1093/infdis/161.6.1203

22. Babady NE, Sloan LM, Vetter EA, Patel R, Binnicker MJ. Percent positive rate of Lyme real-time polymerase chain reaction in blood, cerebrospinal fluid, synovial fluid, and tissue. Diagn Microbiol 
Infect Dis. 2008;62:464-6. http://dx.doi.org/10.1016/ j.diagmicrobio.2008.08.016

23. Molloy PJ, Persing DH, Berardi VP. False-positive results of PCR testing for Lyme disease. Clin Infect Dis. 2001;33:412-3. http://dx.doi.org/10.1086/321911

24. Nocton JJ, Bloom BJ, Rutledge BJ, Persing DH, Logigian EL, Schmid CH, et al. Detection of Borrelia burgdorferi DNA by polymerase chain reaction in cerebrospinal fluid in Lyme neuroborreliosis. J Infect Dis. 1996;174:623-7. http://dx.doi.org/ 10.1093/infdis/174.3.623

25. Molloy PJ, Telford SR III, Chowdri HR, Lepore TJ, Gugliotta JL, Weeks KE, et al. Borrelia miyamotoi disease in the northeastern United States: a case series. Ann Intern Med. 2015;163:91-8. http://dx.doi.org/10.7326/M15-0333

26. Hilton E, DeVoti J, Benach JL, Halluska ML, White DJ, Paxton H, et al. Seroprevalence and seroconversion for tick-borne diseases in a high-risk population in the northeast United States. Am J Med. 1999;106:404-9. http://dx.doi.org/10.1016/S0002-9343(99)00046-7

27. Kalish RA, McHugh G, Granquist J, Shea B, Ruthazer R, Steere AC. Persistence of immunoglobulin $\mathrm{M}$ or immunoglobulin $\mathrm{G}$ antibody responses to Borrelia burgdorferi 10-20 years after active Lyme disease. Clin Infect Dis. 2001;33:780-5. http://dx.doi.org/10.1086/322669

28. Nadelman RB, Wormser GP. Reinfection in patients with Lyme disease. Clin Infect Dis. 2007;45:1032-8. http://dx.doi.org/ $10.1086 / 521256$

29. Lantos PM, Branda JA, Boggan JC, Chudgar SM, Wilson EA, Ruffin F, et al. Poor positive predictive value of Lyme disease serologic testing in an area of low disease incidence. Clin Infect Dis. 2015;61:1374-80. http://dx.doi.org/10.1093/cid/civ584

30. Masters EJ, Grigery CN, Masters RW. STARI, or Masters disease: Lone Star tick-vectored Lyme-like illness. Infect Dis Clin North Am. 2008;22:361-76. http://dx.doi.org/10.1016/j.idc.2007.12.010

31. Forrester JD, Brett M, Matthias J, Stanek D, Springs CB, Marsden-Haug N, et al. Epidemiology of Lyme disease in lowincidence states. Ticks Tick Borne Dis. 2015;6:721-3. http://dx.doi.org/10.1016/j.ttbdis.2015.06.005

32. Steere AC, Dhar A, Hernandez J, Fischer PA, Sikand VK, Schoen RT, et al. Systemic symptoms without erythema migrans as the presenting picture of early Lyme disease. Am J Med. 2003;114:58-62. http://dx.doi.org/10.1016/S0002-9343(02)01440-7
33. Nelson C, Johnson B, Petersen J, Schriefer M, Beard CB, Petersen L, et al. Concerns regarding a new culture method for Borrelia burgdorferi not approved for the diagnosis of Lyme disease. MMWR Morb Mortal Wkly Rep. 2014;63:333.

34. Fallon BA, Pavlicova M, Coffino SW, Brenner C. A comparison of Lyme disease serologic test results from 4 laboratories in patients with persistent symptoms after antibiotic treatment. Clin Infect Dis. 2014;59:1705-10. http://dx.doi.org/10.1093/cid/ciu703

35. Johnson BJ, Pilgard MA, Russell TM. Assessment of new culture method for detection of Borrelia species from serum of Lyme disease patients. J Clin Microbiol. 2014;52:721-4. http://dx.doi.org/10.1128/JCM.01674-13

36. Klempner MS, Schmid CH, Hu L, Steere AC, Johnson G, McCloud B, et al. Intralaboratory reliability of serologic and urine testing for Lyme disease. Am J Med. 2001;110:217-9. http://dx.doi.org/10.1016/S0002-9343(00)00701-4

37. Marques A, Brown MR, Fleisher TA. Natural killer cell counts are not different between patients with post-Lyme disease syndrome and controls. Clin Vaccine Immunol. 2009;16:1249-50. http://dx.doi.org/10.1128/CVI.00167-09

38. Molins CR, Ashton LV, Wormser GP, Hess AM, Delorey MJ, Mahapatra S, et al. Development of a metabolic biosignature for detection of early Lyme disease. Clin Infect Dis. 2015;60:1767-75. http://dx.doi.org/10.1093/cid/civ185

39. Schnell G, Boeuf A, Westermann B, Jaulhac B, Lipsker D, Carapito C, et al. Discovery and targeted proteomics on cutaneous biopsies infected by Borrelia to investigate Lyme disease. Mol Cell Proteomics. 2015;14:1254-64. http://dx.doi. org/10.1074/mcp.M114.046540

40. Halpern MD, Molins CR, Schriefer M, Jewett MW. Simple objective detection of human Lyme disease infection using immuno-PCR and a single recombinant hybrid antigen. Clin Vaccine Immunol. 2014;21:1094-105. http://dx.doi.org/ 10.1128/CVI.00245-14

Address for correspondence: Martin Schriefer, Centers for Disease Control and Prevention, 3156 Rampart Rd, Mailstop P02, Fort Collins, CO 80521, USA; email:mms7@cdc.gov

\section{December 2015: Zoonotic Infections Including:}

- Identifying and Reducing Remaining Stocks of Rinderpest Virus

- Opportunistic Pulmonary Bordetella hinzii Infection after Avian Exposure

- Zoonotic Leprosy in the Southeastern United States

- Infection Risk for Persons Exposed to Highly Pathogenic Avian Influenza A H5 Virus-Infected Birds, United States, December 2014-March 2015

- Influenza A(H6N1) Virus in Dogs, Taiwan

- Novel Waddlia Intracellular Bacterium in Artibeus intermedius Fruit Bats, Mexico

- Tembusu-Related Flavivirus in Ducks, Thailand

- Hendra Virus Infection in Dog, Australia, 2013

- Japanese Macaques (Macaca fuscata) as Natural Reservoir of Bartonella quintana
- Replication Capacity of Avian Influenza A(H9N2) Virus in Pet Birds, Chickens, and Mammals, Bangladesh

- No Evidence of Gouléako and Herbert Virus Infections in Pigs, Côte d'Ivoire and Ghana

- Methicillin-Resistant Staphylococcus aureus Prevalence among Captive Chimpanzees, Texas, USA, 2012

- Increased Number of Human Cases of Influenza Virus A(H5N1) Infection, Egypt, 2014-15

- Kinetics of Serologic Responses to MERS Coronavirus Infection in Humans, South Korea

- Pyrethroid and DDT Resistance and Organophosphate Susceptibility among Anopheles spp. Mosquitoes, Western Kenya

- Japanese Macaques (Macaca fuscata) as Natural Reservoir of Bartonella quintana

\section{http://wwwnc.cdc.gov/eid/articles/issue/21/12/table-of-contents}

